\title{
Undescended Testes in Children: Clinicopathological Study of 32 Cases
}

\author{
Syed Sirajul Islam ${ }^{1}$, Parvez Hassan ${ }^{2}$, Md. Nawshad $\mathrm{Ali}^{3}$, Shah Md Ahsan Shahid ${ }^{4}$ \\ SM Badruddoza ${ }^{5}$, Mostaque Ahmed ${ }^{6}$
}

\begin{abstract}
Objective: To study the presentation, management, histopathological findings and outcome of undescended testes in children. Method: It was a prospective study done in Rajshahi Medical College Hospital and also private clinic in Rajshahi Metropolitan City during the period of $1^{\text {st }}$ December, 2007 to June, 2010. Thirty two children aged 4 months to 13 years with 40 undescended testes were selected in this study. Interventions like Orchidopexy, orchidectomy, herniotomy were done. Results: The age at surgery was four months to 13 years (mean $5.25+$ 0.61 SE years). Nine (28.13\%) had corrected before two years, twenty three $(\mathbf{7 1 . 8 7 \% )}$ after two years. Twenty four testes $(60 \%)$ were palpable and sixteen $(40 \%)$ were non-palpable, none of then cases was diagnosed at birth. Ultrasonography was performed in all cases. Evaluation was done by clinical, sonological, pre-operation and histopathological findings, Laparoscopy was done in one case. The condition was unilateral in $24(75 \%)$ and bilateral in Eight $(25 \%)$. Forty percent of the testes were in the inguinal canal, $34 \%$ at the external ring and $10 \%$ at the internal ring and $16 \%$ in the abdomen. Fifteen (46.87\%) testes were macroscopically smaller in size, four (10\%) testes were atrophic (all were canalicular), one was tumour. Orchidopexy was performed in for 35 undescended testes and orchidectomy for five. Scrotal haematoma developed in 2 cases. Histopathological finding showed no spermatogonia in 25 (78.12\%), among then 23 were above 2 years, 2 were below 2 years. Follow-up period were 6 months to 18 months, no atrophy/retraction was observed.
\end{abstract}

Key words: Undescended testes, clinicopathological study

TAJ 2017; 30: No-2: 26-31

\section{Introduction}

A testes located outside the scrotum is prone to a lot of complications but early detection and corrective surgery is likely to ensure good outcome. The purpose of this study was to determine the pattern of presentation, presenting age, complications, reasons for delay, the surgical treatment offered, histopathological findings and developed awareness for early diagnosis and seeking early treatment.

\section{Materials and Methods}

It was a prospective observational study of 32 patients presenting with undescended testes at Rajshahi Medical College Hospital and Rajshahi Metropolitan City during the period of December 2010 to June 2012. All the patients underwent operative treatment. Demographic profile, clinical pattern, per-operative findings, surgical outcome and histopathological findings were recorded. Data were analyzed using SPSS version 16.

\footnotetext{
${ }^{1}$ Assistant Professor, Department of Paediatric Surgery, Rajshahi Medical College, Rajshahi.

2 Professor, Institute of Biological Sciences, University of Rajshahi, Rajshahi.

${ }^{3}$ Associate Professor \& Head, Department of Paediatric Surgery, Rajshahi Medical College, Rajshahi.

${ }^{4}$ Assistant Professor, Department of Paediatric Surgery, Rajshahi Medical College, Rajshahi.

${ }^{5}$ Professor and Head, Department of Pathology, Rajshahi Medical College, Rajshahi.

${ }^{6}$ Professor, Department of Paediatric Surgery, Rajshahi Medical College, Rajshahi.
} 


\section{Results:}

Total 32 children with 40 undescended testes included in the study. Among them, bilateral 8, right sided 12, left sided 12. Orchiopexy was done in 35 and orchiectomy was done in 5 testes. They were age 4 months to 13 years (mean 5.25+0.61 SE years). Only 9(28.13\%) patients presented at age below 2 years and $23(71.87 \%)$ presented after 2 years of age. Proper antenatal checkup was taken in10 (31.25\%) and no antenatal checkup in $15(47.60 \%)$ cases. Home delivery was $20(62.50 \%)$ and hospital delivery was 12(37.50\%). None of the cases was diagnosed by birth attendants. Incidental findings 26(80\%) by parents/relatives, rest were discovered after developed complications. 16(50\%) patients came from low socio-economic condition. Most of the parents 23(71.87\%) did not seek proper treatment in time, because they have no knowledge about the sequlae of undescended testes. Common complaints was empty scrotum since birth in 22(64.75\%) cases, pain in the inguinal region in 6(18.75\%). 24(60\%) testes were palpable, ultrasound scan shown 10 testes were smaller in size and 10 testes were not visualized, while $10(25 \%)$ could only be located during groin exploration. Intraoperative findings showed normal testicular size in 20(50\%), smaller in size 15(37.50\%), atretic 4(10\%) and tumor was one. Orchiopexy was done in normal/smaller testicular size and orchiectomy for atretic/tumor testes. Biopsy was taken during operation and sent for histopathology. Histopathological findings showed no spermatogonia in 25(78.12\%), among them 23 were above 2 years, 2 were below 2 years. Leydig cell atrophy/absent in 16(50\%), among them 13 were above 2 years and 3 were below 2 years. Malignancy (yolk sac tumor) was detected in one case that was below 2 years of age. Postoperative period was eventful in two patients (hematoma at scrotal site). All patients came for follow-up. Follow-up period were 1month to 12 months, testes were found within the scrotum, no atrophy/retraction was observed.

Table 1: Age at operation for undescended testes in 32 children

\begin{tabular}{|c|c|c|}
\hline Presenting Age group (yrs) & \multicolumn{2}{|c|}{ Frequency } \\
\cline { 2 - 3 } & $\mathbf{N}$ & $\mathbf{\%}$ \\
\hline $0-2$ & 9 & 28.13 \\
\hline$>2-15$ & 23 & 71.87 \\
\hline Total & 32 & 100 \\
\hline
\end{tabular}

The total number of children with undescended tests was 32. Among them 9 (28.13\%) were within 0 -2 years, $23(71.87 \%)$ children were in the age group $>2-15$ years. The delay in presentation is partly reflection of did not realize the important of treatment within 2 two years.

Table 2: Frequency distribution of children by their physical findings

\begin{tabular}{|l|c|c|}
\hline \multirow{2}{*}{\multicolumn{1}{|c|}{ Physical findings }} & \multicolumn{2}{c|}{ Frequency } \\
\cline { 2 - 3 } & $\mathbf{N}$ & $\mathbf{\%}$ \\
\hline Underdeveloped Scrotum & 32 & 100 \\
\hline Impalpable Testes & 15 & 37.50 \\
\hline Palpable Inguinal region & 24 & 60.00 \\
\hline Pelvic Mass & 1 & 2.50 \\
\hline
\end{tabular}




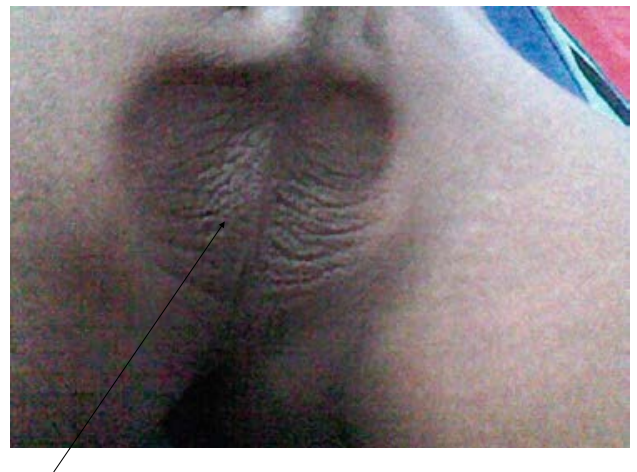

Pic-1Bilateral undescended testes.

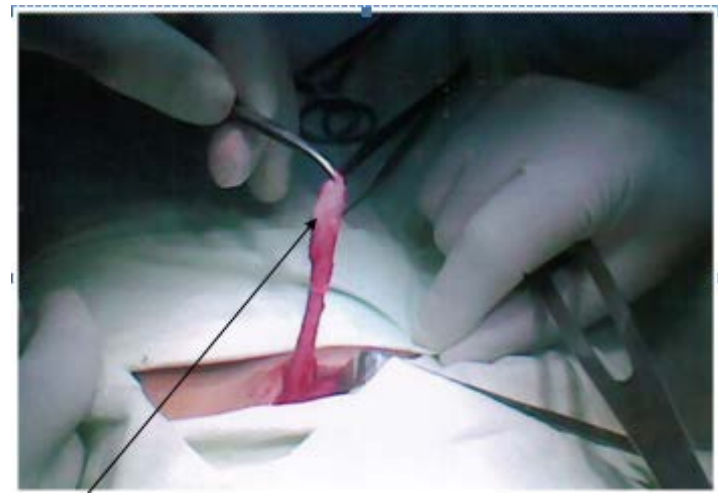

Pic. 3. Atretric/Rudimentry testis
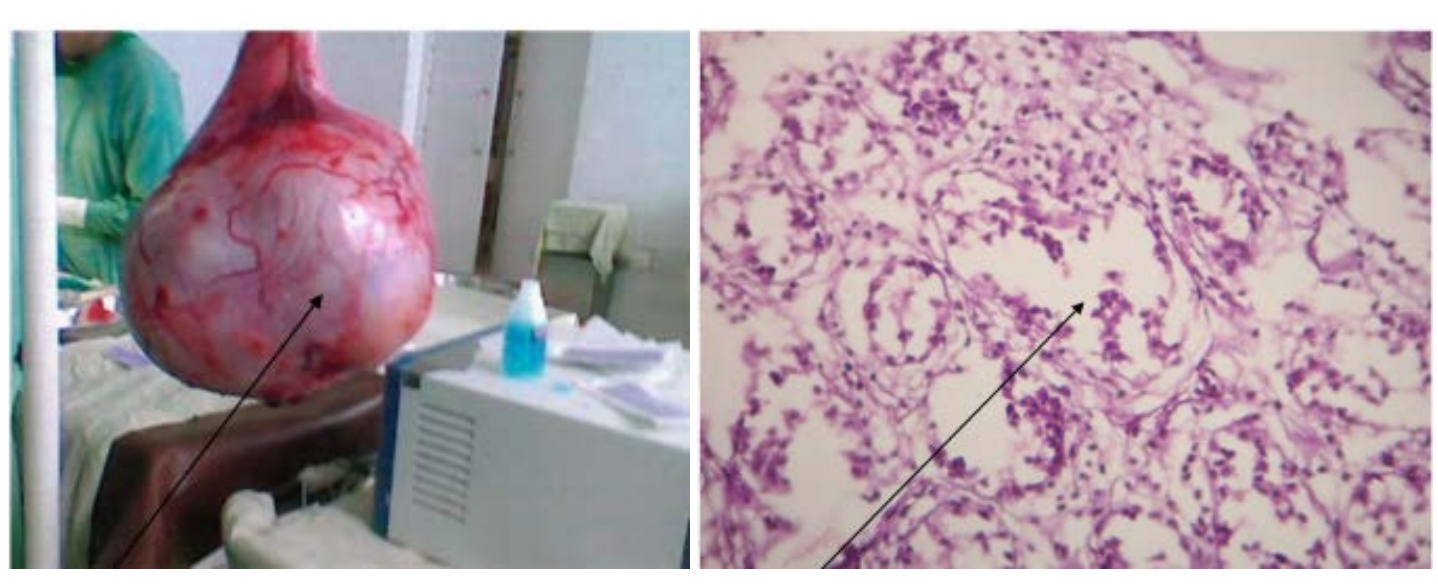

Picture 5: Testicular tumour as a complication Slide 1: Absent Leydig cells

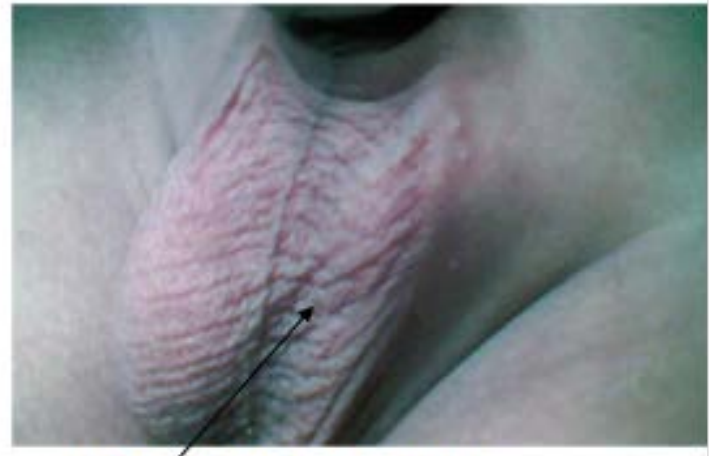

Pic-2.Left sided undescended tests

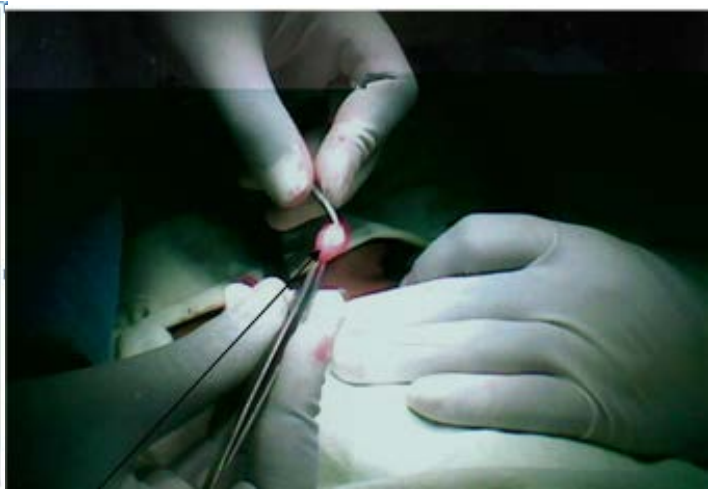

Pic. 4. Atrophy of testis 
Impalpable testes were bilateral three \& unilateral 9, they were below 2 years 5 testes and above 2 years 11 testes. Palpable testes in the inguinal region 24, 8 were below 2 and 16 were above 2 year. Pelvic mass was one.

Table No. 3: Ultrasonogram findings.

\begin{tabular}{|c|c|c|c|c|}
\hline USG findings & Normal & Smaller & Tumor & Total \\
\hline Visualized & 19 & 10 & 1 & 30 \\
\hline Not visualized & 10 & & & 10 \\
\hline Total $=40$ & & & \\
\hline
\end{tabular}

Normal size- 7 were below 2 years and 12 were above 2 years. Smaller size- 8 cases were above 2 years and 2 were below 2 years. Non-visualized- 8 cases were above 2 years and 2 were below 2 years.

Table 4: Frequency distribution of children by operative findings

\begin{tabular}{|c|c|c|}
\hline \multirow{2}{*}{ Size of Testes } & \multicolumn{2}{|c|}{ Frequency } \\
\cline { 2 - 3 } & $\mathbf{N}$ & $\mathbf{\%}$ \\
\hline Normal size & 20 & $50 \%$ \\
\hline Smaller size & 15 & 46.87 \\
\hline Rudimentary/Atretic & 4 & 10.00 \\
\hline Tumor & 1 & 3.13 \\
\hline Total & 40 & 100 \\
\hline
\end{tabular}

Normal size -13 cases were above 2 years and 7 were below 2 years. Smaller/atretic size- 15 cases were above 2 years and 4 were below 2 years. One was tumor.

Table 5: Histopathological findings

\begin{tabular}{|l|c|c|c|c|}
\hline \multirow{2}{*}{ Age group } & \multicolumn{2}{|c|}{ Leydig cell } & Total & P value \\
\cline { 2 - 4 } & Present & Absent & & \multirow{2}{*}{$0 .<0.002$} \\
\hline$<2$ years & 6 & 3 & 9 & \\
\hline$>2$ years & 10 & 13 & 23 & \\
\hline Total & 16 & 16 & 32 & \\
\hline
\end{tabular}

$\mathrm{X} 2=11.59$, $\mathrm{p}$ value $<0.002$. The result is statistically significant.

\section{Discussion:}

Undescended testis is a condition of great concern to pediatric surgeons and urologists owing to the risk of impaired spermatogenesis and consequent infertility later in life. The risk of testicular cancer may be higher in these patients as noted by one report in which ten percent of patients with testicular cancer gave a history of undescended testes. $^{1}$

To avoid the risk of testicular atrophy and infertility, it is now widely agreed that orchiopexy be performed at age 06 months to 12 months. ${ }^{2}$ In the present report however only $28.13 \%$ had 
orchiopexy before 2 years of age and $71.87 \%$ after 2 years of age Majority (71.87\%) had correction after 2 years of age by which time significant morphological changes would have occurred in the testes. These finding are similar to earlier report ${ }^{3-6}$ but at variance with report ${ }^{2,7}$ from developed countries. In an earlier report Zaria ${ }^{3}$ only $11 \%$ of children had surgery before 2 years of age. In a report from Ireland (McKienan et al 1992), the mean age at surgery was 9.5 years but this gradually decreased over the years. In this study, the median age at surgery $5.25 \pm 0.61$ years .The delay in presentation is partly reflection of the level of awareness of the people, financial constraint, none availability of trained birth attendants that can diagnose undescended testes at delivery and parental delay due to ignorance. The reasons for delay include, late presentation, ignorance of initial attending doctors regarding age of optimal treatment, parental delay and lack of recognition by midwives. To improve on the age at surgery, it necessary to educate doctor, midwives and parents as suggested before. ${ }^{6}$ Since many deliveries take place in the traditional home setting, traditional birth attendants should also be taught palpation of the scrotum at birth and refer any suspicious case to a hospital early.

Undescended testes were not discovered by birth attendants in any of our patients, apparently because most of the deliveries (62.50\%) were conducted by traditional birth attendants that had no knowledge about this condition. The parents or relatives discovered on $80 \%$ cases, other discovered after developed complications such as pain, swelling, torsion, malignancy and this is similar to experience also reported earlier work. ${ }^{3}$ In this study 15 (37.50\%) testes were impalpable, the location of the impalpable testes frequently poses challenge. Ultrasonography gives false negative rate as such as $50 \%$ and is believed not to be any better than careful examination by an experienced surgeon. ${ }^{9}$ To date the most reliable diagnostic method for the impalpable testes is laparoscopy. ${ }^{9}$ In our study, ultrasonogram did not locate ten testes; laparoscopy done one bilateral case and other were found during groin exploration. Orchiopexy was performed for 35 undescended testes and five orchidectomy was necessary for four atretic and one was tumor (3 were above 2 years, one below 2 years, tumor also below 2 years). Per operative findings were normal testicular size 20, smaller size 15 , atrectic 4 (table-5.12). Smaller size of testes was more in above 2 years of age. Associated hernia sacs were found with 20 (50\%) testes, hypospadias were 3 cases.

Histopathological findings were no spermtogomia in 26 cases (81.25\%), among them 23 were above 2 years and 3 were below 2 years of age, which is statistically significant $(\mathrm{P}<0.001)$. Leydig cell absent were 16 (50\%) among them 13 were above 2 years of age, 3 were below 2 year of age which was also statistically significant $(\mathrm{P}<0.002)$. Malignancy (yolk sac tumor) was detected in one case that was below 2 years of age. Post-operative periods were eventful in two patients who developed haematoma at scrotal site. All patients came for follow up at 6 and 24 months; in all cases testes were found within the scrotum, no retraction or atrophy was observed.

\section{Conclusion:}

In this study, patients with undescended testis presented late in our hospital because of missed diagnosis at birth. The delay in presentation results in morphological changes in testes, increased rate of complications, increased number of orchiectomy and reduced post-orchiopexy testicular growth. Early diagnosis and treatment is paramount in improving the outcome of patients with undescended testis.

\section{References}

1. Gough $\mathrm{MH}$, Cryptorchidism. Brit J Surg 1989; 76 : 109-112.

2. Hutson JM. Undescended tests, torsion, and varicocele. In: O'Neill JA, Rowe MI, Crofeld JI, Forkalsrud EW; Coras GA, editors. Pediatric surgery $6^{\text {th }}$ ed, Philadelphia: Mosby year Book Inc 2006; P 1193-1214.

3. Ameh EA, Mbibu HN. Management of undescended testes in children in Zaria, Nigeria. East Africa Med J 2000; 77: 485-7.

4. Ahmet Guven, Barry A Kogen, Undescended testis in older boys: J, Ped. Surg Sept, 2008 v-43 issu-9, p-1700-4. 
5. Taha SA, Abdukadar A, Kamal BA, Anikwe RA. Management of unusually high postpubertal presentation of cryptorchidism. Int Surg 1990; 75:105-8.

6. Mabogunje OA. Surgery for undescended testis. East Afr Med J 1986; 63:251-7.

7. Rajendran R, Santhyanji EK Pai R. Age of treatment of undescended testes: A study, J, Indian Medical Assoc 2002; 168: 2590-1.
8. MC Kienan MV, Murphy P.D and Johnston J.G. Ten years review of treatment of undescended testis in the West Ireland. Brit. J. Urol, 1992; 70: 84-49.

9. Cortes D, Thorup JM, Lenz K Beck BL and Nielsen $\mathrm{O}, \mathrm{H}$. Laparoscopy in 100 consecutive patients with 128 impalpable testes. Brit. J .Urol, 1995; 75: 281187.

All correspondence to:

Dr. Syed Sirajul Islam Assistant Professor Department of Paediatric Surgery Rajshahi Medical College Email: syedsislam@hotmail.com 